\title{
Fractures of Capitellum: A Review of 2 Cases Treated by Open Reduction and Internal Fixation with Herbert Screws
}

\author{
Elyazid Houass ${ }^{*}$, M.R.Elgaliou, M.Boufetal, R.A.Bassir, M.Kharmaz, M.O.Lamrani, M.S.Berrada
}

Departement of Orthopedic Surgery and Trauma, Ibn Sina University Hospital Center Rabat Morocco

Faculty of Medecine and Pharmacy-University Mohamed V Rabat Morocco

DOI: $10.36347 /$ sjams.2020.v08i11.044

| Received: 15.11.2020 | Accepted: 26.11.2020 | Published: 29.11.2020

*Corresponding author: Elyazid Houass

Abstract

Isolated capitellar fractures are an articular lesion with a frontal fracture line. This fracture is uncommon and the diagnosis is often missed. We report two cases of capitellar fracture type 1 according to the classification of Bryan Morrey, treated operatively by open reduction and internal fixation using herbert screws within $48 \mathrm{~h}$ after injury, The elbow was immobilized for 4 weeks. The patient regained full range of movement at 12 weeks post operatively. There were no instances of infection or avascular necrosis.

Keywords: Capitellum fracture, herbert screws, open reduction, internal fixation.

Copyright $(\mathcal{C} 2020$ The Author(s): This is an open-access article distributed under the terms of the Creative Commons Attribution 4.0 International License (CC BY-NC 4.0) which permits unrestricted use, distribution, and reproduction in any medium for non-commercial use provided the original author and source are credited.

\section{INTRODUCTION}

Isolated fractures of the capitulum are rare and may go unnoticed. They represent $1 \%$ of all elbow fractures and $6 \%$ of humerus fractures [1], it requires internal fixation to restore the anatomic integrity of the elbow joint and precise reduction to maximize articular congruency and diminish the potential for arthrosis [2].

We present the cases of a 22-year-old woman and 28 years old man with hahn steinahl fracture or capitulum type 1 , The fractures were treated by open reduction and internal fixation. The follow-up period ranged from 3 to 4.5 years, all patients had a stable, pain-free elbow with good range of motion at followup, the result of this form of management was found to be satisfactory.

\section{Patient and Observation}

\section{Observation number 1}

A 22 year old right handed lady of presented to the emergency department with a history of fall on her left elbow. There was pain and swelling around the elbow. The movements at the elbow were painful and restricted. There was no neurovascular deficit. The radiographs (Figure 1) revealed a fracture of the capitellum which was reconfirmed as an isolated Type I (Hahn-Steinthal) fracture by a CT scan (Figure 2). A decision for open reduction and internal fixation was taken. Using the lateral approach, the fracture was fixed using two herbert screws (figure 3 and 4). The elbow was immobilized in a plaster for 4 weeks; this was followed by a progressive elbow mobilization programme guided by the physiotherapist. She was followed up at 4 weeks, 6 weeks, 3 months, 6 months and 12 months. She attained full range of movement at 3 months, with no further complications later and there was no evidence of avascular necrosis or degenerative change.

\section{Observation number 2}

A 28 year old right handed man presented to the emergency department with a history of fall on the outstretched hand. There was pain and swelling around the elbow. The movements at the elbow were painful and restricted. There was no neurovascular deficit. The radiographs (Figure 5) revealed a fracture of the capitellum which was reconfirmed as an isolated Type I (Hahn-Steinthal) fracture by a CT scan (Figure 6). A decision for open reduction and internal fixation was taken. Using the lateral approach, the fracture was fixed using two herbert screws (figure 7 and 8). The elbow was immobilized in a plaster for 4 weeks; this was followed by a progressive elbow mobilization programme guided by the physiotherapist. She was followed up at 4 weeks, 6 weeks, 3 months, 6 months and 12 months. He attained full range of movement at 3 months (Fig 3) with no further complications later and there was no evidence of avascular necrosis or degenerative change. 


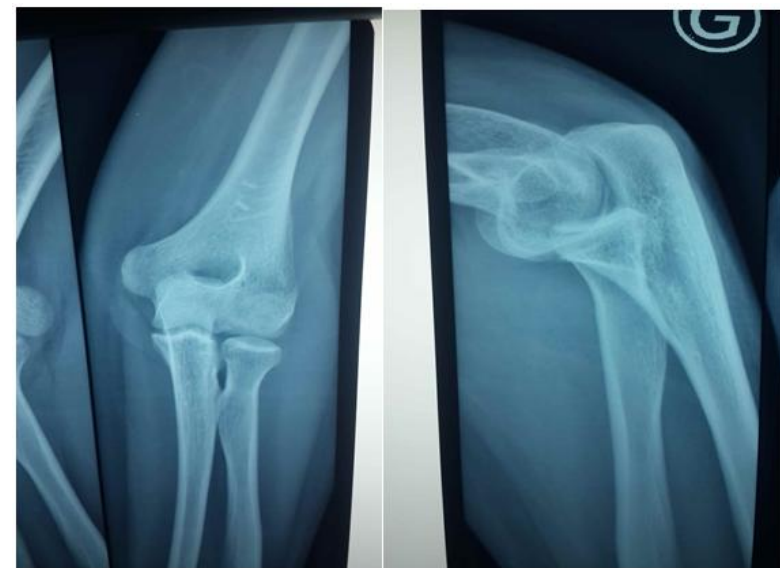

Fig-1: A conventional AP and lateral elbow $x$-ray revealing a fracture of the capitellum

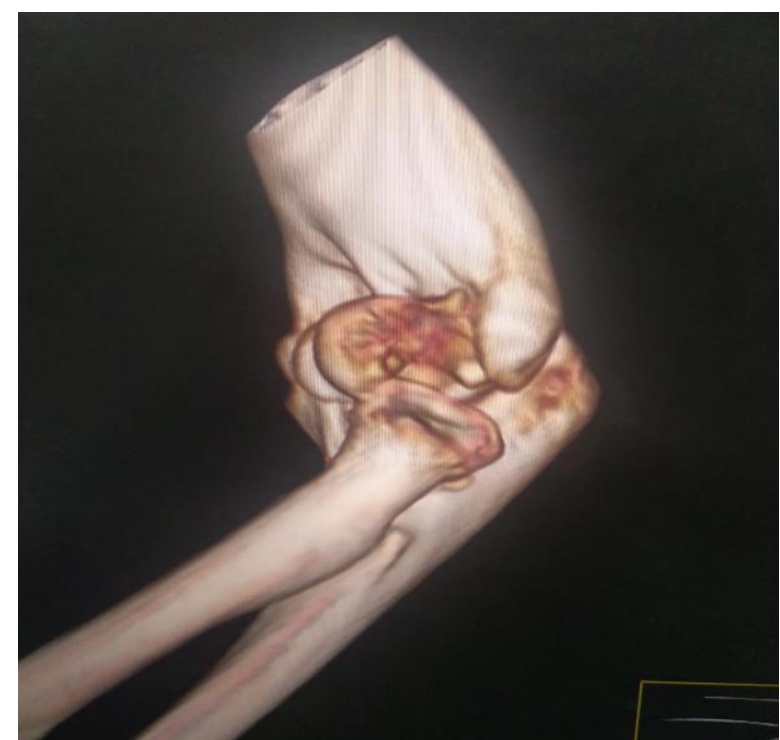

Fig-2: Elbow CT scan confirming an isolated Type I (HahnSteinthal) fracture

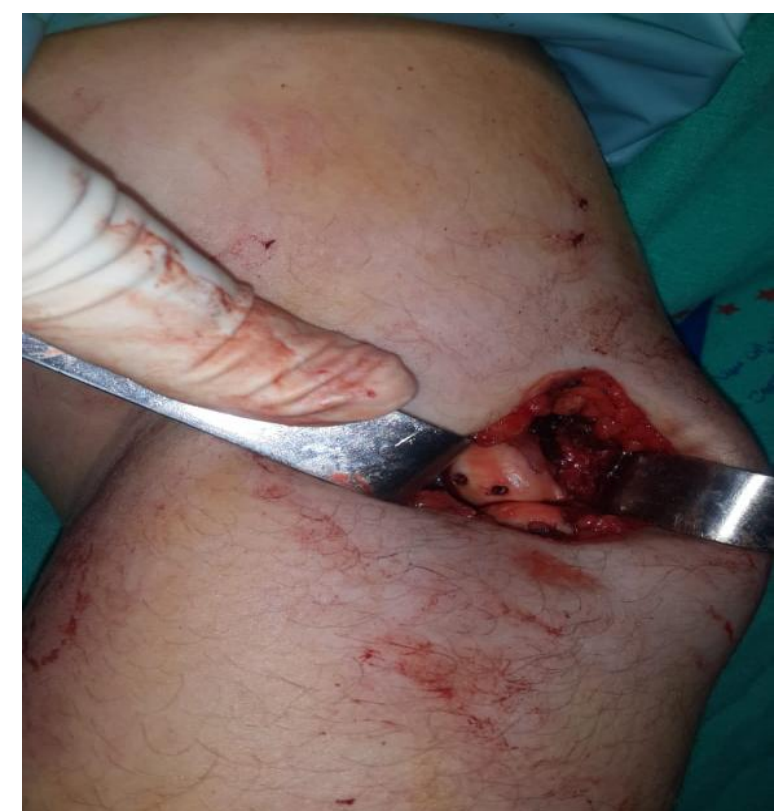

Fig-3: Per operative picture showing the anatomic reduction and the inernal fixation by 2 herbet screws

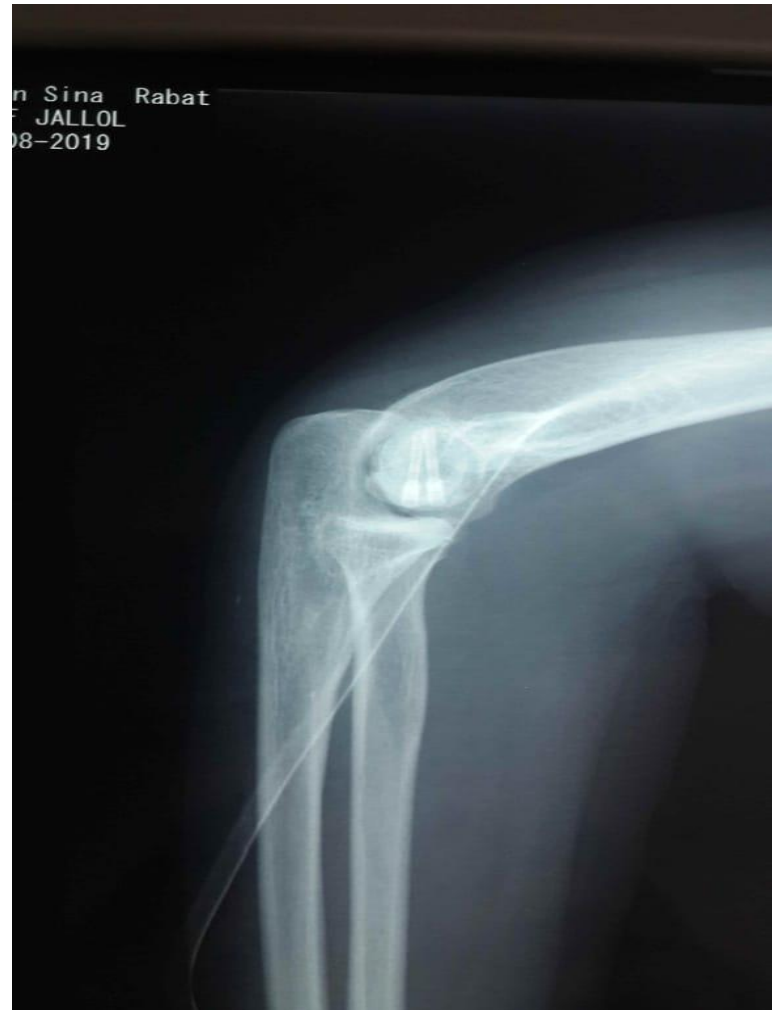

Fig-4: The conventional x-ray postoperaive control

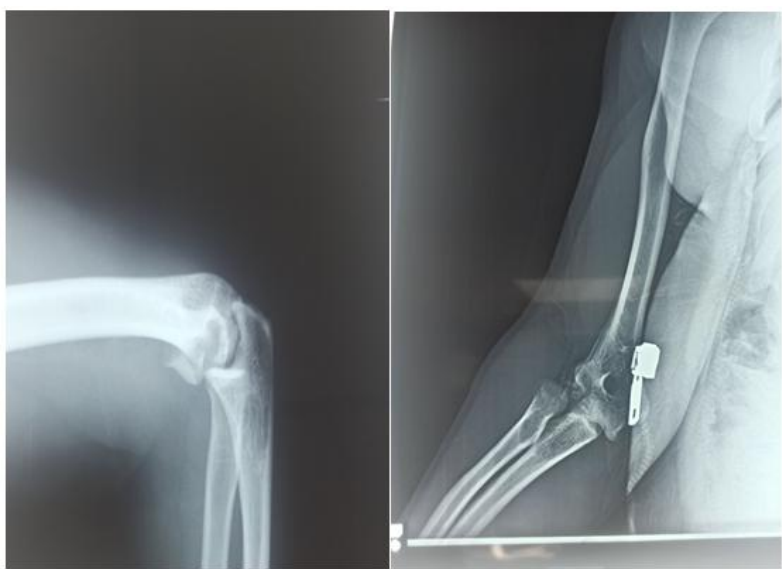

Fig-5: Conventional AP and lateral elbow x-ray revealing a fracture of the capitellum

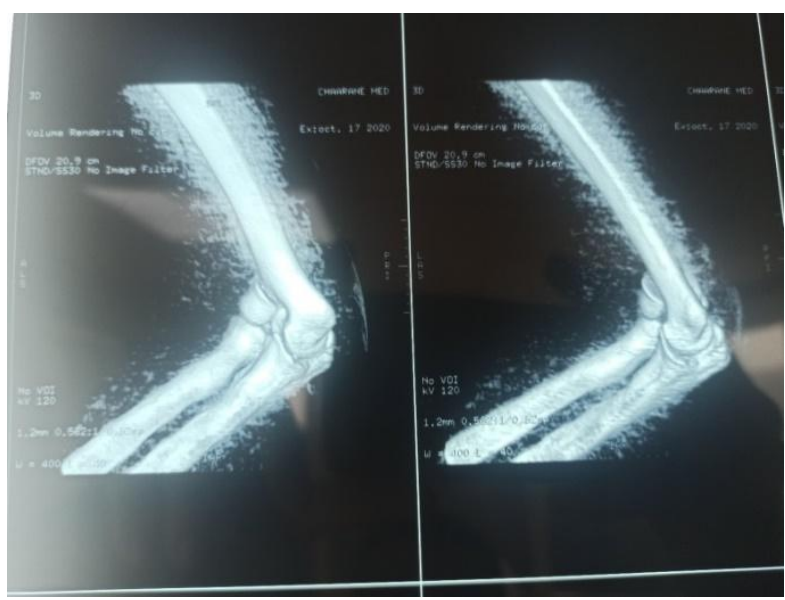

Fig-6: Elbow CT scan confirming an isolated Type I (HahnSteinthal) fracture 


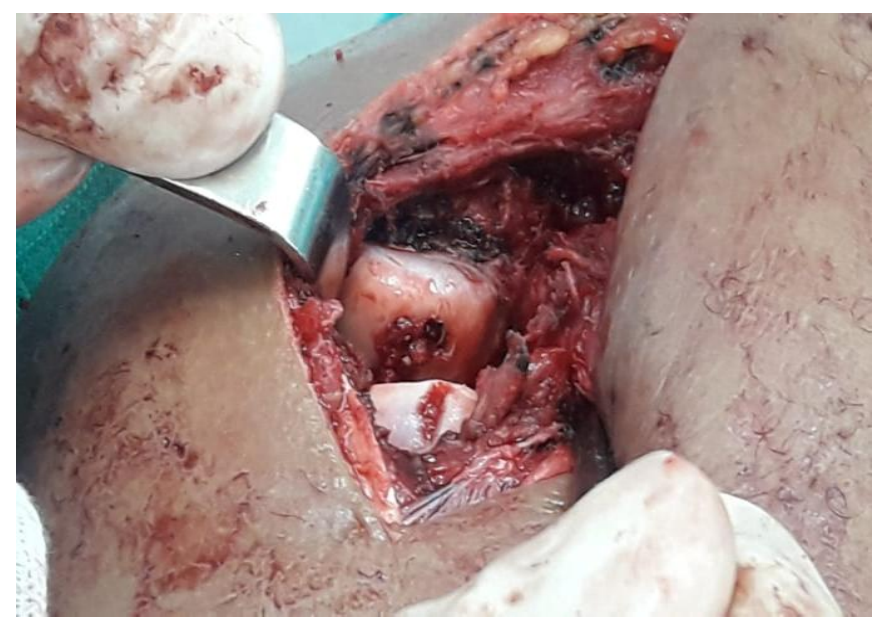

Fig-7: Per operative picture showing the anatomic reduction and the inernal fixation by 2 herbet screws

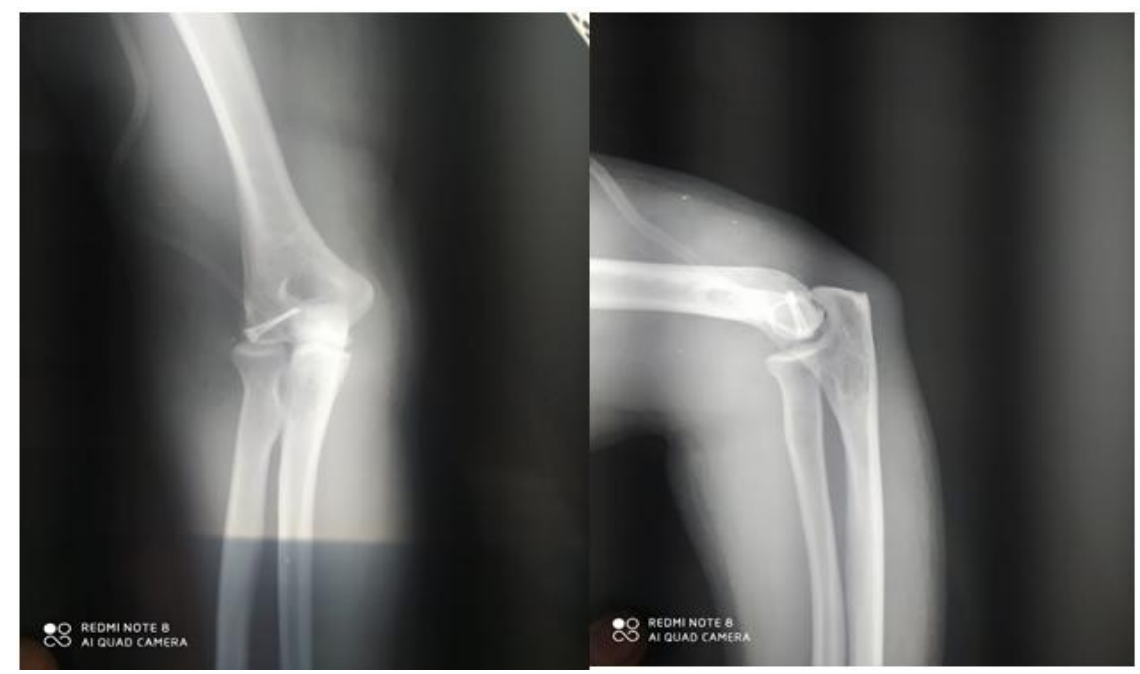

Fig-8: The conventional x-ray postoperative control

\section{DisCUSSION}

Patients with capitellar fractures usually present with pain and swelling of the elbow after injury. Fractures of the capitellum are frequently missed $[2,3]$. They are not obvious on anteroposterior radiographs because the fracture line may not be recognized against the background of the distal humerus. They are best seen on a true lateral view, CT scan with sagittal and coronal plane reconstructions is recommended to define the medial extent of the fracture, articular impaction, and metaphyseal and condylar comminution [3,4]. The contributing factors encountered are the ulna-valgus and ulna-recurvatum $[5,6]$.

A fall on the outstretched hand or directly on the elbow produces a shear force fracturing the capitellum in the coronal plane [7]. These fractures can be classified according to the McKee modification of the Bryan and Morrey classification [8].

Accurate reduction and stable fixation of the fracture and early postoperative mobilization has been reported to provide good results. Herbert screws allow rigid fixation at the fracture site, provide fracture site compression and need not be removed later $[2,9,10]$.

Limitation of flexion and extension and residual pain are the most common complications of capitellar fracture [11, 12]. Accurate reduction of the fracture, stable fixation and immediate mobilization are the keys to achieve optimum functional results.

Avascular necrosis, feared as a major complication, is uncommon after surgical treatment of these fractures despite the fact that these fragments usually have no soft tissue attachments [13]. In our review, we didn't get any case of avascular necrosis.

\section{CONCLUSION}

Open reduction and internal fixation are the treatment of choice for Hahn Steinthal fracture. Stabilization by Herbert's screw, which is a modern method, gives satisfactory results because it allows strong inter-fragmentary compression, early mobilization, and early functional result of the elbow. Removal of the osteosynthesis material is rarely necessary. 


\section{REFERENCE}

1. Mehdian H, McKee MD. Fractures of capitellum and trochlea. Orthopedic Clinics. 2000 Jan 1;31(1):115-27.

2. Mahirogullari M, Kiral A, Solakoglu C, Pehlivan O, Akmaz I, Rodop O. Treatment of fractures of the humeral capitellum using Herbert screws. Journal of Hand Surgery. 2006 Jun;31(3):320-5.

3. Singh AP, Singh AP, Vaishya R, Jain A, Gulati D. Fractures of capitellum: a review of 14 cases treated by open reduction and internal fixation with Herbert screws. International orthopaedics. 2010 Aug 1;34(6):897-901.

4. Ruchelsman DE, Tejwani NC, Kwon YW, Egol KA. Coronal plane partial articular fractures of the distal humerus: current concepts in management. JAAOS-Journal of the American Academy of Orthopaedic Surgeons. 2008 Dec 1;16(12):716-28.

5. Pogliacomi F, Concari G, Vaienti E. HahnSteinthal fracture: report of two cases. Acta biomedica: Atenei Parmensis. 2005 Dec;76(3):178-84.

6. Nawghare SP, Baidyaray R, Neyt JG. HahnSteinthal fracture: a case report. Cases Journal. 2008 Dec 1;1(1):239.

7. Dendane MA, Gorinda H, Amrani A, El Alami ZF. La fracture de Hahn-Steinthal chez l'adolescent.
Une lésion rare à ne pas méconnaître. Journal de traumatologie du sport. 2011 Dec 1;28(4):251-4.

8. Bryan RS. Fractures of the distal humerus. The elbow and its disorders. 1985.

9. Silveri CP, Corso SJ, Roofeh J. Herbert screw fixation of a capitellum fracture. A case report and review. Clinical orthopaedics and related research. 1994 Mar(300):123-6.

10. Richards RR, Khoury GW, Burke FD, Waddell JP. Internal fixation of capitellar fractures using Herbert screws: a report of four cases. Canadian journal of surgery. Journal canadien de chirurgie. 1987 May;30(3):188.

11. Stamatis E, Paxinos O. The treatment and functional outcome of type IV coronal shear fractures of the distal humerus: a retrospective review of five cases. Journal of orthopaedic trauma. 2003 Apr 1;17(4):279-84.

12. Goodman HJ, Choueka J. Complex coronal shear fractures of the distal humerus. Bulletin-Hospital for Joint Diseases. 2004;62(3-4):85-9.

13. Singh AP, Dhammi IK, Garg V, Singh AP, Shuang-ming S. Outcome of surgical treatment of type IV capitellum fractures in adults. Chinese Journal of Traumatology. 2012 Aug 1;15(4):201-5. 